\title{
Scar Treatment with Lasers: A Review and Update
}

\author{
Ru'aa Al Harithy • Kucy Pon
}

Published online: 4 May 2012

(C) Springer Science+Business Media, LLC 2012

\begin{abstract}
Scars affect millions of people every year with a great impact on patients, both physically and psychologically. Treatment of scars poses a great challenge for physicians. The evolution of lasers has provided a treatment option for many types of scars. In this paper we review the literature on different laser treatment option for scars and comment on our practice.
\end{abstract}

Keywords Lasers · Scar · Treatment · Management

\section{Introduction}

Scars are a very common complication of acne, burns, surgeries, and traumatic injuries affecting millions of people every year. The appearance of scars can be very disturbing to patients both physically and psychologically. Many treatment options and modalities have been employed for reduction and prevention of scar formation, including topical steroids, intralesional steroids, cryosurgery, interferon, 5flurouracil, silicone gel, radiation, and surgeries. There is no general consensus in the literature as to what is the optimal treatment. The evolution of lasers in the last few decades has showed clinical and cosmetic benefits for patients and may be a good treatment option for many types of scars.

\section{R. Al Harithy $\cdot$ K. Pon $(\bowtie)$}

SunnyBrook Health Sciences Centre,

2075 Bayview Avenue Suite M1-700,

Toronto, ON M4N 3M5, Canada

e-mail: kucy.pon@utoronto.ca

R. Al Harithy

e-mail: Ruaa.alharithy@utoronto.ca

\section{Pathophysiology of Scar Formation}

Understanding the pathophysiology of scar formation is important for the clinician who deals with scar treatment. Wound healing progresses through three stages: inflammation, proliferation, and maturation. Inflammation occurs immediately after injury with the activation of the coagulation cascade. Platelets are the first cells to appear after wounding. They release chemoattractive factors and vasoactive mediators that stimulate migration of inflammatory cells including neutrophils and macrophages. Neutrophils produce matrix metalloproteinases (MMPs) and collagenase, which cause excessive tissue loss in the wound area, leaving an area of tissue devoid of matrix that is subsequently replaced by scar tissue during the remodeling phase [1].

After 48 to $72 \mathrm{~h}$ the healing process transitions into the proliferative phase that lasts 3 to 6 weeks. Fibroblasts and endothelial cells migrate and proliferate within the wound site to form a connective tissue rich in blood vessels. Simultaneously, keratinocytes grow inward from the wound edges to cover the wound with a new epithelial layer. After the deposition of an early extracellular matrix (ECM), this matrix starts to remodel its collagen framework by cell apoptosis and cell maturation to obtain the scar ultimate strength. This process can last up to 2 years after the initial injury [2].

Excessive inflammation in healing tissue is responsible for increased scar formation. Scarring acne shows a predominantly $\mathrm{CD} 45 \mathrm{RO}+$ memory $\mathrm{T}$ cell immune response, which is initially small and ineffective, but later becomes increased and activated in resolving lesions. In contrast with non-scarring acne, the cellular infiltrate is large and active with few memory $\mathrm{T}$ cells in early lesion, which subsides in the resolution phase [3]. 


\section{Classification of Scars}

Proper classification of scars is essential for determining proper laser treatment choice and protocol. Scar type, texture, morphology, and color determine the choice of laser parameter and help predict the number of treatments required. For the purpose of this article we discuss scars in three main categories: 1) hypertrophic scars and keloids, 2) acne atrophic scars, and 3) burn scars.

\section{Laser Treatment of Scars}

Lasers were first used in the treatment of scars in 1978. The first laser used to treat hypertrophic scars and keloids was the continuous wave argon [4]. Despite encouraging early reports, subsequent studies showed limited efficacy and high incidence of side effects [5]. Then, the neodymium: yttrium-aluminium-garnet $(\mathrm{Nd}: Y A G, 1064 \mathrm{~nm})$ laser and continuous wave $\mathrm{CO}_{2}$ laser $(10,600 \mathrm{~nm})$ were described in the early $1980 \mathrm{~s}$ as an alternative to argon by selectively inhibiting collagen production [6]. However, results showed failure to inhibit keloid formation and recurrence of lesions 1 year after treatment [7]. The theory of selective photothermolysis, which was introduced in early 1980s, has resulted in the invention of pulsed lasers that provided target selectivity, reducing the thermal damage and scarring [8].

More recently, the concept of fractional photothermolysis (FP) was introduced in 2003 as an option for low risk, effective resurfacing techniques. Fractionated lasers work by thermally altering a "fraction" of the skin, leaving up to $95 \%$ of skin untouched, which repopulates the ablated columns of tissue permitting rapid epidermal repair. FP induces small three-dimensional zones of thermal damage known as microscopic treatment zones (MTZs). Water is the target chromophore for all available fractional devices on the market at this time. For FP, as the energy of the treatment is increased, the depth of penetration increases, and as the treatment level is increased, the density of the spots is increased. Densities can be reported as either percentage of coverage or number of MTZs per square centimeter [9, 10॰]. Fractionated lasers are divided into ablative and non-ablative fractional resurfacing based on the wavelength affinity for water. Ablative fractional resurfacing (AFR) lasers have high affinity for water and these include the fractionated $\mathrm{CO}_{2}$ 10,600 nm, erbium:yttrium aluminum garnet (Er:YAG $2990 \mathrm{~nm}$ ) and yttrium scandium gallium garnet (YSGG $2790 \mathrm{~nm}$ ) lasers. Those with less affinity for water are classified as non-ablative fractionated lasers and include the following wavelengths: $1410 \mathrm{~nm}, 1440 \mathrm{~nm}, 1540 \mathrm{~nm}$, and $1550 \mathrm{~nm}[10 \bullet, 11 \bullet]$.

\section{Lasers for Hypertrophic Scars and Keloids}

Hypertrophic scars are firm, red or pink raised scars confined within the margins of the original injury. They are usually most prevalent within the first month after injury and may regress over time. In contrast, keloids are raised, reddish-purple, nodular scars, firmer than hypertrophic scars, and keloids extend beyond the margins of the original wound and do not regress over time [13].

Many different lasers have been tried in the treatment of hypertrophic scars and keloids with variable efficacy. The most common laser used in the treatment of hypertrophic scar and keloids has been the pulsed dye laser (PDL 585$595 \mathrm{~nm}$ ), which is considered the laser of choice in treating pigmented and hypertrophic scars [12••]. The most likely mechanism by which PDL works is through selective photothermolysis in which energy is absorbed by oxyhemoglobin leading to coagulation necrosis $[8,14,15]$. It has also been shown that PDL treatments increase MMP-13 activity and reduce TGF-beta expression, fibroblast proliferation, collagen type III, and controls the degree of angiogenesis within the wound and assists in minimizing scarring [16, 17]. Furthermore, PDL has been recently shown to up regulate P53 expression, which arrests fibroblast proliferation cell cycle [18]. When treating hypertrophic scars and keloids, PDL is used primarily to reduce erythema but has also been shown to reduce scar volume and improve scar texture as well as reduce pain and pruritus [15]. When comparing results of the two different PDL wave lengths it has been shown in a systematic review by Vrijman et al. [19••] that PDL $585 \mathrm{~nm}$ has a low efficacy for the treatment of hypertrophic scars when compared to PDL $595 \mathrm{~nm}$, which has moderate efficacy [19••]. Keloids do show minimum improvement with PDL but seem to show enhanced clinical results when combined with intralesional corticosteroids or 5-fluorouracil injections [20].

The parameter used for hypertrophic scars and keloids are non-overlapping pulses ranging from 6 to $7.5 \mathrm{~J} / \mathrm{cm}^{2}$ ( $7 \mathrm{~mm}$ spot) or 4.5 to $5.5 \mathrm{~J} / \mathrm{cm}^{2}$ (10 mm spot), which should be applied over the entire surface of the scar (Table 1) [21]. Reducing pulse duration from $40 \mathrm{~ms}$ to $0.45 \mathrm{~ms}$ has been shown to be more efficacious in reducing scar volume and improving pliability but showed no difference in scar erythema [22]. Energy density should be decreased by $10 \%$ in darker-pigmented patients or when treating scars in sensitive areas, such as anterior chest and neck [23]. The most common post-PDL treatment side effects are purpura that can last up to 3 to 7 days, blistering can occur, as well as pigment alteration, which is more common in darkly pigmented skin. Treatments are typically done at 6- to 8-week intervals to allow for adequate healing time, but longer intervals may be needed for darker pigmented patients and patients with sensitive area scars [24••]. Most hypertrophic 
Table 1 Summary of laser choices and settings for different scar types

\begin{tabular}{|c|c|c|}
\hline Scar type & Laser choice & Settings \\
\hline \multirow[t]{3}{*}{ Hypertrophic scars and keloids } & PDL $(585-595 \mathrm{~nm})$ & $\begin{array}{l}7 \mathrm{~mm} \text { spot, } 6.0-7.5 \mathrm{~J} / \mathrm{cm}^{2} \\
10 \mathrm{~mm} \text { spot, } 4.5-5.5 \mathrm{~J} / \mathrm{cm}^{2} \\
0.45 \mathrm{~ms}\end{array}$ \\
\hline & QS Nd:YAG $532 \mathrm{~nm}$ & $\begin{array}{l}3-4 \mathrm{~mm} \text { spot, } \\
1.8-2.8 \mathrm{~J} / \mathrm{cm}^{2}, \\
10 \mathrm{~ms}\end{array}$ \\
\hline & Non-ablative fractional $(1540 / 1550 \mathrm{~nm})$ & $\begin{array}{l}40-70 \mathrm{~J} / \mathrm{cm}^{2} \\
\text { treatment level } 5-9, \\
14 \%-27 \% \text { coverage, } \\
8 \text { passes }\end{array}$ \\
\hline \multirow[t]{5}{*}{ Atrophic acne scars } & Nd:YAG (1320 nm) & $\begin{array}{l}10 \mathrm{~mm} \mathrm{spot}, \\
12-20 \mathrm{~J} / \mathrm{cm}^{2}, \\
350 \mathrm{~ms}\end{array}$ \\
\hline & Nd:YAG (1064 nm) & $12 \mathrm{~mm}, 50 \mathrm{~J} / \mathrm{cm}^{2}, 50 \mathrm{~ms}$ \\
\hline & Diode $1450 \mathrm{~nm}$ & $\begin{array}{l}6 \mathrm{~mm}, 8-14 \mathrm{~J} / \mathrm{cm}^{2}, \\
250 \mathrm{~ms}\end{array}$ \\
\hline & Er:glass(1540 nm) & $\begin{array}{l}35-40 \mathrm{~mJ} / \mathrm{MTZ} \\
\text { treatment level 7-10 }\end{array}$ \\
\hline & Fractionated $\mathrm{CO}_{2}$ & $\begin{array}{l}20-100 \mathrm{MJ}, \\
200-1600 \mathrm{MTZ} / \mathrm{cm}^{2}, \\
30-70 \mathrm{~mJ}, \\
\text { treatment level 4-11, } \\
20-50 \mathrm{~mJ} \text { off face }\end{array}$ \\
\hline \multirow[t]{2}{*}{ Post-burn scars } & PDL $(585-595 \mathrm{~nm})$ & $\begin{array}{l}7 \mathrm{~mm} \text { spot, } 5.0-8.8 \mathrm{~J} / \mathrm{cm}^{2}, \\
10 \mathrm{~mm} \text { spot, } 4.0-5.0 \mathrm{~J} / \mathrm{cm}^{2} \\
1.5 \mathrm{~ms}\end{array}$ \\
\hline & Non-ablative fractional (1540 nm) & $\begin{array}{l}21-40 \mathrm{~J} / \mathrm{cm}^{2}, 10 \mathrm{~mm} \\
15 \mathrm{~ms}\end{array}$ \\
\hline
\end{tabular}

scars require an average of two laser treatments to achieve a $50 \%$ to $80 \%$ improvement in redness and thickness [12••].

Other non-ablative lasers that have been reported in the treatment of hypertrophic scars and keloids are the $532 \mathrm{~nm}$ and $1064 \mathrm{~nm} \mathrm{Nd:YAG.} \mathrm{Although} \mathrm{the} \mathrm{long-pulsed} 1064 \mathrm{~nm}$ Nd:YAG showed mixed and conflicting results in the treatment of hypertrophic scars and keloids [25], the Q-switched $1064 \mathrm{~nm} \mathrm{Nd:YAG} \mathrm{and} \mathrm{frequency-doubled} \mathrm{Nd:YAG} 532 \mathrm{~nm}$ showed promising results by selectively suppressing collagen production in the fibroblast and inducing collagen remodeling by thermal damage [26, 27]. The $532 \mathrm{~nm} \mathrm{Nd:YAG} \mathrm{has} \mathrm{a}$ wavelength that is close to the oxyhemoglobin absorption peak and has been shown to have a comparable favorable result when compared to $585 \mathrm{~nm}$ PDL [28].

Ablative laser resurfacing with $\mathrm{CO}_{2}$ or Er:YAG lasers has showed moderate improvement of hypertrophic scars and keloids [19••]. These ablative lasers target water in the tissue, resulting in tissue vaporization. However, these lasers are falling out of favor due to the prolonged downtime and side effects [9].

Fractional lasers on the other hand are gaining popularity and have been successfully utilized in the treatment of hypertrophic scars. In a recent randomized controlled trial the efficacy of $1550 \mathrm{~nm}$ erbium-doped fiber laser (Fraxel Restore laser [Solta Medical, Hayward, CA]) was assessed in the treatment of hypertrophic scars. Results showed an overall improvement in scars after 4 treatments at 2-week intervals. Change in scar texture showed the most significant improvement compared to erythema and pigmentation. Treatments benefits were more pronounced at 3 months of evaluation compared to 1 month post-split scar and treated half was better, so there was additional benefit from laser. This study also showed younger scars, defined as scars less than 2 years, showed better overall improvement compared to older scars (over 6 years), and low-density settings (40 mJ, treatment level 5, $14 \%$ coverage) were as effective as high-density settings (40 mJ, treatment level 9, $26 \%$ coverage) [29]. Fractional laser treatments work by inducing a wound response mediated by several heat shock proteins, proliferation of fibroblasts, and subsequent new collagen formation [30].

Limited head-to head comparative studies exist. A comparative randomized split scar study was conducted by Tierney et al. [31•]. In this study, the $1550 \mathrm{~nm}$ erbium doped fiber laser (Fraxel RS [Reliant Technologies, Mountain 
View, CA]) at $70 \mathrm{~mJ}(23 \%$ coverage $)$ was found to be superior to PDL (7.5 mJ, $10 \mathrm{~mm}, 0.45 \mathrm{~ms})$ with an overall global improvement of $75 \%$ in scars treated with Fraxel RS compared to PDL, which showed $53 \%$ improvement [31•].

In our clinic, we typically treat hypertrophic scars with a combination of pulsed dye laser followed by intralesional triamcinolone injection during the same visit (Table 2). Patients typically require three to five sessions with treatments being spaced out at 4- to 6-week intervals. For stubborn hypertrophic scars that do not respond to a series of pulsed dye laser treatments, Fraxel is offered as second-line treatment.

\section{Atrophic Acne Scars}

Acne scarring can be broadly categorized based on the two causes of acne scar formation. Increase tissue formation, which leads to hypertrophic scars and keloids, or the more common cause, loss or damage of tissue, which leads to the formation of atrophic scars [32].

Jacob et al. [33] further classified atrophic acne scars into three types: ice pick, rolling, and boxcar scar (Fig. 1). The ice pick scar is narrow $(<2 \mathrm{~mm})$, deep with tracts to the dermis or subcutaneous tissue; these are commonly seen on

Table 2 The authors' practice of treating scars

Indication Options

Atrophic scars (ice pick, rolling, and boxcar)

Hypertrophic scars

Surface/superficial bumpiness/textural problems
If deep, the best choice is excision or subcision followed by injectable filler. For boxcar, punch elevation may be an option. Fully-ablative lasers $\left(\mathrm{CO}_{2}\right.$, Er:YAG) can help, especially if shallow. Fractional ablative lasers can be helpful if full ablation is not possible. Deep ice pick scar may benefit from CROSS.

If there is redness, PDL may be used after ablative laser treatment is complete. PDL-595 is a second choice option for thickness, and first choice for redness. If ILK is chosen, it may be preferable to wait until the thickness is reduced before treating the redness, as ILK itself may induce telangiectasia that may be amenable to PDL.

Ablation with $\mathrm{CO}_{2}$ is the treatment of choice, with fractional an option if full ablation is not tolerable. Other ablative techniques like dermabrasion or chemical peels are alternatives. PDL may provide color improvements if used at least 6 weeks after ablation is complete.
Thickness is best managed with ILK.
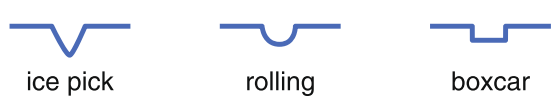

Fig. 1 Atrophic acne scars

the cheeks. Rolling scars are 4 to $5 \mathrm{~mm}$ in diameter, caused by abnormal fibrous strands anchoring the dermis to the subcutaneous tissue, leading to superficial rolling of the overlying skin. Boxcar scars are 1.5 to $4 \mathrm{~mm}$ round or oval depressions with sharply demarcated edges. These can be subdivided into shallow $(<0.5 \mathrm{~mm})$ or deep $(>0.5 \mathrm{~mm})$ [33]. In atrophic scars, the goal of laser treatment is to smooth the scar texture and stimulate collagen formation.

Ablative lasers were the first lasers used to treat atrophic acne scars. $\mathrm{CO}_{2}$ and Er:YAG lasers work by targeting intraand extra-cellular water. These laser systems emit highenergy densities within short pulses that affect tissue vaporization with limited thermal conduction to surrounding skin. A predictable amount of epidermis and papillary dermis is vaporized, leading to eventual remodeling of the dermal collagen and elastin and neocollagenesis [34]. $\mathrm{CO}_{2}$ laser resurfacing vaporizes tissue at a depth of 20 to $60 \mu \mathrm{m}$ and zones of thermal necrosis ranging another 20 to $50 \mu \mathrm{m}$. At the cellular level, $\mathrm{CO}_{2}$ laser enhances upregulation of procollagens I and II, interleukin 1-b, TNF-alpha, TGF-beta1, and matrix metalloproteinases (MMPs)-1, $-3,-9$, and -13 [35].

Er:YAG $(2940 \mathrm{~nm})$ is 10 times more selective for water than $\mathrm{CO}_{2}$ laser due to its shorter wavelength, reduces residual thermal damage [36]. Er:YAG at $5 \mathrm{~J} / \mathrm{cm}^{2}$ vaporizes tissue at depth of 20 to $25 \mu \mathrm{m}$ with an additional 5 to $10 \mu \mathrm{m}$ zone of thermal necrosis [37]. $\mathrm{CO}_{2}$ laser resurfacing has improved moderate to severe atrophic acne scars in $50 \%$ to $80 \%$ with an ongoing collagen remodeling going on afterwards for 1 year [38]. Treatments with ablative lasers require prophylactic antimicrobial therapy, and have been associated with extended recovery periods, prolonged erythema, and transient hyperpigmentation. Re-epithelialization takes 4 to 7 days with Er:YAG and 7 to 10 days with $\mathrm{CO}_{2}$ laser. Head-to-head studies of the $\mathrm{CO}_{2}$ and Er:YAG lasers showed that $\mathrm{CO}_{2}$ has superior results but Er:YAG is better tolerated with less downtime [9, 34].

Non-ablative lasers induce thermal injury to the papillary and reticular dermis with preservation of the overlying epidermis. This allows for scar remodeling without the extended recovery times. Nd:YAG $1320 \mathrm{~nm}$, Q-switch Nd:YAG $1064 \mathrm{~nm}$, diode laser $1450 \mathrm{~nm}$, and erbium glass $1540 \mathrm{~nm}$ lasers has been used in atrophic acne scar treatments. PDL $585 \mathrm{~nm}$ has not been shown to be effective in treating atrophic scars due to its shorter wavelength, which can not penetrate deep enough to stimulate sufficient collagen remodeling [23].

The most widely used non-ablative lasers used for atrophic scars treatment are Nd:YAG $1320 \mathrm{~nm}$ and diode $1450 \mathrm{~nm}$. Treatment usually involves three consecutive

CROSS chemical reconstruction of skin scars 
monthly treatment sessions with the greatest improvement noticed between 3 and 6 months after the final laser treatment. Improvement $40 \%$ to $45 \%$ has been observed after either $1320 \mathrm{~nm} \mathrm{Nd:YAg}$ or $1450 \mathrm{~nm}$ diode laser treatment. Degree of improvement was validated by clinical assessment, patient satisfaction survey, histologic evaluations, and skin texture measurements [23].

Fractional ablative and fractional non-ablative lasers has been used with variable success in the treatment of atrophic scars [39]. The first fractionated laser used and the one most studied is the $1550-\mathrm{nm}$ non-ablative fractionated device that uses an erbium doped fiber laser (Fraxel Restore [Reliant Technologies, San Diego, CA]). Other available nonablative fractionated lasers are LUX $1540 \mathrm{~nm}$ (Palomar Medical Technologies, Burlington, MA,USA) and Affirm 1440 nm Nd:YAG (Nd:YAG, Cynosure Inc, Westford, MA, USA). The latter two use stamping technology as opposed to scanning mode used in the Fraxel. Their mechanism of action and basic theories however are similar, and few studies compare the different fractional non-ablative devices making it difficult to state which one is superior.

Alster et al. [10•] reports a $25 \%$ to $50 \%$ improvement in atrophic acne scars appearance after a single treatment with the $1550 \mathrm{~nm}$ erbium-doped fiber laser and a $51 \%$ to $75 \%$ improvement in $87 \%$ of patients who received at least three treatments.

During treatment, patients experience pain requiring pretreatment topical anesthesia and cooling of the skin surface during treatment. Post-treatment side effects vary based on used treatment setting. In general, mild erythema and edema is experienced 1 to 3 days post-treatment followed by bronzing and slight scaling of the skin.

Following ablative fractionated treatments, patients can expect longer duration of erythema and edema, bleeding and oozing and downtime can be up to 14 days. Other reported side effects are acneiform eruption, activation of herpes simplex, and post-inflammatory hyperpigmentation in darker skin types, which may be avoided by using conservative setting and reduce treatment density (percentage coverage) [40, 41].

Atrophic acne scars have shown improvement when treated with fractional ablative $\mathrm{CO}_{2}$. A mean reduction of $66 \%$ in atrophic acne scars depth was seen following 2 to 3 treatments, with the maximum improvement seen several months after treatment [34, 42]. Fractionated $\mathrm{CO}_{2}$ lasers offer the advantage of inducing thermal dermal coagulation at depths extending greater than both traditional ablative and fractionated non-ablative devices. Up to $1 \mathrm{~mm}$ in depth can be achieved with fractionated $\mathrm{CO}_{2}$, thus inducing greater collagen production and dermal remodeling than nonablative fractionated photothermolysis [42]. Persistent collagen remodeling with wound healing response occurs up to 3 months after in vivo fractional $\mathrm{CO}_{2}$ ablative laser [43].
The combination of ablative fractional $\mathrm{CO}_{2}$ laser and a non-ablative long-pulse $1064 \mathrm{~nm} \mathrm{Nd:YAG} \mathrm{laser} \mathrm{has} \mathrm{allowed}$ for a lower setting of the fractional $\mathrm{CO}_{2}$ laser and has yielded the best results, with fewer complications compared to fractional $\mathrm{CO}_{2}$ laser alone [44].

We agree that the most improvement of atrophic acne scars is seen with ablative laser treatments; however, due to the higher incidence of side effects and adverse events, and the prolonged down time, ablative treatments are not practical for most patients. We typically treat with the fractionated erbium doped fiber (Fraxel Restore) or fractional $\mathrm{CO}_{2}$.

\section{Burn Scars}

Burn scars are some of the most disfiguring scars seen in clinical practice. These scars are often partially or completely deprived of adnexal structures, which are important for re-epithelialization of ablated skin surface [45].

The use of PDL (585-595 nm) in burn scars has been shown to significantly improve pruritus and pain within the scars [46], improve scar pliability and texture, reduce erythema and histologically reduce sclerosis without change in number of fibroblast [47]. Despite the positive results of PDL therapy in some burn scars, PDL laser penetration is limited to approximately $1.2 \mathrm{~mm}$, which limits its effect in thick hypertrophic scars $(>1 \mathrm{~cm})$ when used alone $[46,48]$. PDL is best introduced in burn patients 3 to 6 months postburn. Results show decreased erythema after 1 to 2 treatments and best candidates are patients with lighter skin types (Fitzpatrick types I-III). Prophylactic treatment of patients within the first few weeks post-burn injury showed better cosmesis of scarring, faster resolution of scar stiffness and erythema, but no significant difference was seen in long-term assessment (post 3 months) [48, 49].

Fractional non-ablative and ablative laser resurfacing has been utilized to treat burn scars. In a randomized control trial the effectiveness of $1540 \mathrm{~nm}$ fractional erbium:glass using Lux 1540 nm (StarLux-300TM; Palomar Medical Technologies, Burlington, MA) laser was assessed. Patients were treated with 3 treatments, at 4-week intervals using 10-mm handpiece, $15 \mathrm{~ms}, 21$ to $40 \mathrm{~J} / \mathrm{cm}^{2}, 3$ to 4 passes, and results showed moderate to significant improvement in skin texture compared to untreated controls. The authors noticed that superficial burns did better than deep burns, which could be a result of the utilized laser's ability to cause thermal damage to a depth of 400 to $1000 \mathrm{~nm}$, leaving the deeper fibrous tissues unaffected [50].

Ablative fractional resurfacing has the ability to remove both epidermal and dermal tissues, which theoretically can remove burn scar tissue, and subsequent collagen remodeling could normalize the texture, elasticity, and color of the scar [51]. Few case reports have shown that ablative 
fractional resurfacing is safe and effective in treatment of burn scars; however further studies are needed to determine parameters [45].

Treatment with ablative full field $\mathrm{CO}_{2}$ and Er:YAG has been used but has been associated with prolonged recovery times and contradicting results [52]. Burn scars, especially ones that are new, need to be treated gently. In our clinic, we typically use the pulsed dye laser first to improve erythema and texture. After a series of treatments, and as the burn scar matures, fractional ablative and non-ablative lasers may be used to further improve scar texture (Table 2).

\section{Conclusions}

Lasers represent one of the most successful modalities for scar treatments. Sufficient knowledge of efficacy, safety, and limitation of different lasers available is essential for physicians treating scars. It is important to discuss with patients that currently there is no treatment that offers complete resolution of scars and often more than one modality may be necessary to reach satisfactory results.

In this review we have examined the literature on scar treatments with lasers; most data are based on case reports and only limited randomized controlled trials are available. Furthermore, there is no consensus on what "improvement in scars" means. Different authors use different scales and outcome measurements, which makes comparing results impossible. More controlled trials are required, universal scale of scars improvement levels is needed, as are comparative studies.

Disclosure No conflicts of interest relevant to this article were reported.

\section{References}

Papers published recently of particular interest has been highlighted as:

- Of importance

•- Of major importance

1. Niessen FBMD, Spauwen PHMMD, Schalkwijk JPD, Kon MMD. On the nature of hypertrophic scars and keloids: a review. Plast Reconstr Surg. 1999;104(5):1435-58.

2. Singer AJ, Clark RA. Cutaneous wound healing. N Engl J Med. 1999;341(10):738-46.

3. Holland DB, Jeremy AHT, Roberts SG, Seukeran DC, Layton AM, Cunliffe WJ. Inflammation in acne scarring: a comparison of the responses in lesions from patients prone and not prone to scar. Br J Dermatol. 2004;150(1):72-81.

4. GinsbachG, Kohnel W. The treatment of hypertrophic scars and keloids by Argon laser: clinical data and morphologicalfindings. Plast Surg Forum.1978;1:61-67.

5. HulsbergenHenning JP, Roskam Y, van Gemert MJ. Treatment of keloids and hypertrophic scars with an argon laser. Lasers Surg Med. 1986;6(1):72-5.
6. Aberge RP, Dwyer RM, Meeker CA, et al. Laser treatment of keloids: a clinical trial and in vitro study with $\mathrm{Nd}$ :YAG laser. Lasers Surg Med. 1984;4(3):291-5.

7. Lim TC, Tan WT. Carbon dioxide laser for keloids. Plast Recontr Surg. 1991;88(6):1111.

8. Anderson RR, Parrish JA. Selective photothermolysis: precise microsurgery by selective absorption of pulsed radiation. Science. 1983;220(4596):524-7.

9. Alexiades-Armenakas MR, Dover JS, Arndt KA. The spectrum of laser skin resurfacing: Nonablative, fractional, and ablative laser resurfacing. J Am Acad Dermatol 2008;58(5):719-737.

10. - Alster TS, Tanzi EL, Lazarus M. The Use of Fractional Laser Photothermolysis for the Treatment of Atrophic Scars. Dermatologic Surgery 2007;33(3):295-299. This is a welldesigned study assessing the efficacy of Fraxel on atrophic scars

11. - Geronemus R. Ablative and Fractional Ablative Lasers. Dermatol Clin 2009 -10-01;27(4):479-489. This is a review article discussing ablative and fractional ablative lasers, and their efficacy and side effects.

12. - Elsaie ML, Choudhary S. Lasers for scars: a review and evidence-based appraisal. Journal of Drugs in Dermatology: JDD 2010; 9(11):1355-1362. This is an updated review article discussing scar treatment with lasers with an evidence-based approach.

13. Wolfram D, Tzankov A, Pulzl P, Piza-katzer H. Hypertrophic scars and keloids - a review of their pathophysiology, risk factors, and therapeutic management. Dermatol Surg. 2009;35 (2):171-81.

14. Alster TS, Handrick C. Laser treatment of hypertrophic scars, keloids, and striae. Semin Cutan Med Surg. 2000;19(4):287-92.

15. Bouzari N, Davis SC, Nouri K. Laser treatment of keloids and hypertrophic scars. Int J Dermatol 2007;46(1):80-88.

16. Kuo YR, Jeng SF, Wang FS, Chen TH, Huang HC, Chang PR, et al. Flashlamp pulsed dye laser (PDL) suppression of keloid proliferation through down-regulation of TGF-betal expression and extracellular matrix expression. Lasers in Surgery \& Medicine 2004;34(2):104-108.

17. Kuo YR, Wu WS, Wang FS. Flashlamp pulsed-dye laser suppressed TGF-beta1 expression and proliferation in cultured keloid fibroblasts is mediated by MAPK pathway. Lasers in Surgery \& Medicine 2007 Apr;39(4):358-364.

18. Zhibo X, Miaobo Z. Molecular mechanism of pulsed-dye laser in treatment of keloids: an in vitro study. Adv Skin Wound Care 2010 Jan;23(1):29-33.

19. ••Vrijman C, van Drooge AM, Limpens J, Bos JD, van der Veen JPW, Spuls PI, et al. Laser and intense pulsed light therapy for the treatment of hypertrophic scars: a systematic review. Br J Dermatol 2011;165(5):934-942. This is one of the few systematic reviews available on this topic. Discusses lasers and IPL in the treatment of hypertrophic scars.

20. Connell PG, Harland CC. Treatment of keloid scars with pulsed dye laser and intralesional steroid. J Cutan Laser Ther 2000 Sep;2 (3):147-150

21. Zeikus PS. Principles and practices in cutaneous laser surgery. J Am Acad Dermatol 2006;55(1):181-181.

22. Manuskiatti W, Wanitphakdeedecha R, Fitzpatrick RE. Effect of Pulse Width of a 595-nm Flashlamp-Pumped Pulsed Dye Laser on the Treatment Response of Keloidal and Hypertrophic Sternotomy Scars. Dermatologic Surgery 2007;33(2):152-161.

23. Tanzi EL, Alster TS. Laser treatment of scars. Skin Therapy Lett 2004 Jan;9(1):4-7.

24. •- Khatri KA, Mahoney DL, McCartney MJ. Laser scar revision: A review. J Cosmet Laser Ther 2011;13(2):54-62. This is an updated review on laser scar revision.

25. Atiyeh BS. Nonsurgical Management of Hypertrophic Scars: Evidence-Based Therapies, Standard Practices, and Emerging Methods. Aesth Plast Surg 2007;31(5):468-492. 
26. Cho SB, Lee SJ, Chung WS, Kang JM, Kim YK. Treatment of burn scar using a carbon dioxide fractional laser. Journal of Drugs in Dermatology: JDD 2010 Feb;9(2):173-175.

27. Castro DJ, Abergel RP, Meeker C, Dwyer RM, Lesavoy MA, Uitto J. Effects of the Nd:YAG laser on DNA synthesis and collagen production in human skin fibroblast cultures. Ann Plast Surg 1983 Sep;11(3):214-222.

28. Bowes LE, Nouri K, Berman B, et al. Treatment of pigmented hypertrophic scarswith the $585 \mathrm{~nm}$ pulsed dye and the $532 \mathrm{~nm}$ frequency-doubled Nd:YAG laser in the Q-switchedand variable pulse modes: a comparative study. Dermatol Surg. 2002;28:714-9.

29. Lin JY, Warger WC, Izikson L, Anderson RR, Tannous Z. A prospective, randomized controlled trial on the efficacy of fractional photothermolysis on scar remodeling. Lasers in Surgery \& Medicine 2011 Apr;43(4):265-272.

30. Hantash BM, Bedi VP, Kapadia B, Rahman Z, Jiang K, Tanner H, et al. In vivo histological evaluation of a novel ablative fractional resurfacing device. Lasers in Surgery \& Medicine 2007 Feb;39 (2):96-107.

31. - Tierney E, Mahmoud BH, Srivastava D, Ozog D, Kouba DJ. Treatment of surgical scars with nonablative fractional laser versus pulsed dye laser: a randomized controlled trial. Dermatologic Surgery 2009 Aug;35(8):1172-1180. This is a randomized controlled trial examining the two most common laser modalities used in the treatment of surgical scars.

32. Rivera AE. Acne scarring: a review and current treatment modalities. J Am Acad Dermatol. 2008;59(4):659-76.

33. Jacob CI, Dover JS, Kaminer MS. Acne scarring: A classification system and review of treatment options. J Am Acad Dermatol 2001;45(1):109-117.

34. Chapas AM, Brightman L, Sukal S, Hale E, Daniel D, Bernstein $\mathrm{LJ}$, et al. Successful treatment of acneiform scarring with $\mathrm{CO} 2$ ablative fractional resurfacing. Lasers in Surgery \& Medicine 2008 Aug;40(6):381-386.

35. Orringer JS, Kang S, Johnson TM, Karimipour DJ, Hamilton T, Hammerberg C, et al. Connective tissue remodeling induced by carbon dioxide laser resurfacing of photodamaged human skin. Arch Dermatol 2004; 140(11):1326-1332.

36. Rogge FJ, Cambier B. Safe and effective treatment of problem scars with the purely thermal non-ablative Er:YAG laser scar mode. J Cosmet Laser Ther. 2008;10(3):143-7.

37. Walsh JT, Flotte TJ, Deutsch TF. Er:YAG laser ablation of tissue: Effect of pulse duration and tissue type on thermal damage. Lasers Surg Med 1989;9(4):314-326.

38. Bernstein LJ, Kauvar ANB, Grossman MC, Geronemus RG. Scar Resurfacing with High-Energy, Short-pulsed and Flashscanning Carbon Dioxide Lasers. Dermatologic Surgery 1998;24(1):101-107.
39. Weiss ET, Chapas, Anne Brightman, Lori Hunzeker, Christopher Hale, Elizabeth K., Karen JK, Bernstein LG, Roy G. Successful Treatment of Atrophic Postoperative and Traumatic Scarring With Carbon Dioxide Ablative Fractional Resurfacing: Quantitative Volumetric Scar Improvement. Arch Dermatol 2010;146(2): 133-140.

40. Bodendorf MO, Grunewald S, Wetzig T, Simon JC, Paasch U. Fractional laser skin therapy. Journal der Deutschen Dermatologischen Gesellschaft 2009 Apr;7(4):301-308.

41. Graber EM, Tanzi EL, Alster TS. Side Effects and Complications of Fractional Laser Photothermolysis: Experience with 961 Treatments. Dermatologic Surgery 2008;34(3):301-307.

42. Hunzeker CM, Weiss ET, Geronemus RG. Fractionated CO2 laser resurfacing: our experience with more than 2000 treatments. Aesthet Surg J. 2009;29(4):317-22.

43. Chan NP, Ho SG, Yeung CK, Shek SY, Chan HH. Fractional ablative carbon dioxide laser resurfacing for skin rejuvenation and acne scars in Asians. Lasers in Surgery \& Medicine 2010 Nov;42(9):615-623.

44. Kim S, Cho K. Clinical trial of dual treatment with an ablative fractional laser and a nonablative laser for the treatment of acne scars in Asian patients. Dermatol Surg. 2009;35(7): 1089-98.

45. Waibel J, Beer K. Ablative fractional laser resurfacing for the treatment of a third-degree burn. Journal of Drugs in Dermatology: JDD 2009 Mar;8(3):294-297.

46. Allison KP, Kiernan MN, Waters RA, Clement RM. Pulsed dye laser treatment of burn scars. Burns 2003;29(3):207-213.

47. Alster TS, Nanni CA. Pulsed dye laser treatment of hypertrophic burn scars. Plastic \& Reconstructive Surgery 1998 Nov;102 (6):2190-2195.

48. Parrett BM, Donelan MB. Pulsed dye laser in burn scars: current concepts and future directions. Burns 2010 Jun;36(4):443-449.

49. Liew SH, Murison M, Dickson WA. Prophylactic treatment of deep dermal burn scar to prevent hypertrophic scarring using the pulsed dye laser: a preliminary study. Ann Plast Surg 2002 Nov;49 (5):472-475.

50. Hædersdal M, Moreau KER, Beyer DM, Nymann P, Alsbjørn B. Fractional nonablative $1540 \mathrm{~nm}$ laser resurfacing for thermal burn scars: A randomized controlled trial. Lasers Surg Med. 2009;41 (3):189-95.

51. Bowen RE. A novel approach to ablative fractional treatment of mature thermal burn scars. Journal of Drugs in Dermatology: JDD 2010 Apr;9(4):389-392.

52. Eberlein A, Schepler H, Spilker G, Altmeyer P, Hartmann B. Erbium:YAG laser treatment of post-burn scars: Potentials and limitations. Burns. 2005;31(1):15-24. 